\title{
Study on Disease Distribution and Test Results of Tuberculosis of Regional Control Project in Guangxi, China
}

\author{
Guosheng Su, Lida Mo*, Xiaolu Luo, Wanhong Huang, Shanqiu Wei, Hanzhen Su \\ The Fourth People's Hospital Clinical Laboratory Nanning Guangxi, Guangxi Medical University Affiliated to \\ Infectious Diseases Hospital of Nanning, Guangxi AIDS Clinical Treatment Center (Nanning), Nanning, China \\ Email: $1773398578 @ q q . c o m$, luoxiaolu2007@126.com, asjbwan@sina.com, sherryxhl1234@163.com, \\ xuhuanling1234@163.com
}

Received 26 August 2015; accepted 17 October 2015; published 20 October 2015

Copyright @ 2015 by authors and Scientific Research Publishing Inc.

This work is licensed under the Creative Commons Attribution International License (CC BY). http://creativecommons.org/licenses/by/4.0/

(c) (i) Open Access

\section{Abstract}

The purpose of this study is to investigate the disease distribution of tuberculosis in national regional project. 960 patients were selected from national tuberculosis control program who took treatments in the Fourth People's Hospital Clinical Laboratory in Nanning Guangxi from January to November in 2013. Then we observed all those patients' disease distribution and analyzed all the lab test indexes. We analyzed the results according to gender and age distribution. From the age distribution, we found that the incidence was lower at the age of 40 or younger, while higher incidence occurred to patients over 40 years old. There is statistical significance comparing these two age groups. $P$ is less than 0.001 . Disease distribution: 731 patients were infected with TB; 21 patients were co-infected with tuberculosis (TB) and HIV. 196 patients were co-infected with TB and fungal. 12 patients were co-infected with TB, HIV and fungal. From the laboratory testing, we know there were 87 patients whose liver function indexes were abnormal. There were 192 patients whose blood RT indexes were abnormal. The liver function and blood RT indexes of patients with co-infection were higher than those infected purely. There is statistical significance in comparison $P<0.05$. The study indicates that patients with older age are more likely infected with tuberculosis. In addition, there are a high proportion of patients with co-infection among these patients in this study. Meanwhile, the liver functions and blood RT indexes of patients combining with infection are higher than those infected TB purely. Prompt clinical prevention and treatment should be under reasonable inspections. General analysis can enable us to investigate more effective treatment plan. Then the best treatment result will be obtained.

\footnotetext{
${ }^{*}$ Corresponding author.
}

How to cite this paper: Su, G.S., Mo, L.D., Luo, X.L., Huang, W.H., Wei, S.Q. and Su, H.Z. (2015) Study on Disease Distribution and Test Results of Tuberculosis of Regional Control Project in Guangxi, China. Advances in Infectious Diseases, 5, 125131. http://dx.doi.org/10.4236/aid.2015.54015 


\title{
Keywords
}

\author{
National Tuberculosis Control Project, Tuberculosis (TB), HIV, Fungi (FV), Combined with \\ Infection
}

\section{Introduction}

In recent years, the incidence of tuberculosis (TB) has been on a rising trend year by year. Furthermore, because resistance of body is becoming lower, TB is susceptible to be invaded and attacked by a variety of bacteria and viruses, which lead to co-infection disease. As a consequence, the whole body organs are badly influenced and it does much harm to our health. At the same time, TB seriously affects people's life and causes serious damage to people's life. To prevent and control TB is becoming more and more significant, and leads to great pressure as well. Therefore, there is much point in investigating the distributions and laboratory diagnosis of disease, which can treat TB patients effectively [1]-[3]. The national planning tuberculosis control project is such a program that according to the situation of TB epidemic in our country our government invests money to prevent and control TB. Currently, although there are many studies on blood routine and blood biochemical analysis, the distribution of the joint disease analysis is nearly not reported. In recent years, the incidence of TB has been on a rising trend. To prevent and control TB is taken more and more seriously [4]. In order to investigate the disease distribution of tuberculosis, we selected 960 patients from national tuberculosis control program who took treatments in tuberculosis clinic of our hospital and at the inpatient department from January to November in 2013. Here are the results.

To understand the disease distribution of tuberculosis in national regional project, this research was carried out from January 2013 to November 2013 in our hospital. All the lab test indexes are analyzed and the results will show as follows.

\section{Materials and Methods}

\subsection{The Objects of Study}

We selected 960 patients of national tuberculosis control program who took treatments in tuberculosis clinic of our hospital and at the inpatient department from January to November in 2013. Among those objectives, there were 739 cases of males and 221 cases of females accounting for $76.98 \%$ and $23.02 \%$ separately. Tuberculosis pathology of all objectives represents as low fever, malaise and night sweats, accompanying cough, expectoration, hemopstysis, chest tightness, chest pain, etc. The imaging, sputum, blood, body fluids, n/med tuberculosis bacterium were used to confirm TB. And the standard of choosing the objects in this study is that there is mycobacterium tuberculosis on the culture or smear.

\subsection{Instrumentation and Reagents}

Instrumentation: Olympus BX51 microscope was used to test sputum smears and other body fluids. Acid dye was provided by Zhuhai Mr Cable biological technology co., Ltd. Sysmex 2000i blood instrument and related reagents were used to finish blood routine examination. Automatic biochemical analyzer, Germany Roche PPE800 and related reagents were used to examine liver function. All reagents were used before their production validity.

\subsection{Selection Methods}

Select 960 patients of national tuberculosis control program who took treatments in tuberculosis clinic of our hospital and at the inpatient department from January to November in 2013. Then we observed all those patients' disease distribution. Artificially, it could be divided into TB group, TB co-infected with HIV group, TB coinfected with fungi and TB co-infected with HIV and FV, etc. And then all the lab test indexes analyzed according to state specified standards, such as the imaging test, specimen culturing, and blood testing and main indexes of liver function, like WBC (white blood) cell, NE (neutrophilicgranulocyte), LYMlymphocyte), EO (basophile granulocyte), EA (eosinophile granulocyte), RBC (red blood cell), HBG (hemoglobin), PLT (blood 
platelet), TBIL (total bilirubin), DBIL (bilirubin direct; conjugated bilirubin) and so on.

This study obtained support and approval from Guangxi Association of STD (sexually transmitted disease) and AIDS (acquired immune deficiency syndrome) prevention (No. 49852135-5). During this research, we protected patients' privacy. If not, the related research studies were approved by Guangxi Association of STD and AIDS prevention and those patients' approval.

\subsection{Statistical Treatment}

Statistic process software GraphPad Prism 19.0 was used to analyze statistically. Patient's age, blood routine and liver function indicators are for measuring data, which are under normal distribution. The comparison of technical data was tested by chi-square. Data are analyzed by $\mathrm{t}$ inspection and $\mathrm{x}^{2}$ inspection and results showed with the average $\mathrm{X} \pm \mathrm{S}$. Take $\mathrm{P}<0.05$ as the statistically significant difference.

\section{Results}

Among those 960 TB patients, there are 739 cases of male accounting for $76.98 \%$ and female of 221 cases, accounting for $23.02 \%$. Comparison of prevalence rate between male and female showed chi-square $=559.01, \mathrm{P}=$ 0.00012. The differences of prevalence rate between male and female make a statistical significance. While the age of distribution of disease is as follows: 28 cases from 0 to 20 years old, 132 cases from 21 to 30 years old, 141 cases from 31 to 40 years old, 168 cases from 41 to 50, 191 cases from 51 to 60, 189 cases from 61 to 70 and 139 cases above 71 years old. According to this age distribution, we can know that under the age of 40 , the incidence of TB infection is relatively low, reported for 273 cases, accounting for $28.44 \%$. While higher incidence occurring over age of 40 , there were 687 cases, accounting for $71.56 \%$. Comparing this two age distribution, chi-square $=357.08, \mathrm{P}=0.000187$ showed that the difference is statistically significant. In terms of distribution of disease, this research mainly focused on statistical significant complications, general bacterial infections are not included in this study. According to different TB infections, we divided those patients into four groups. They were 731 cases of pure TB infection group, accounting for 76.14\%, 21 cases of tuberculosis complicated by HIV infection group, accounting for 2.19\%, 196 cases of merger of fungal infection group accounting for $0.42 \%$, and 12 cases with HIV and TB fungal infection group, accounting for $1.25 \%$. In the laboratory tests, there were 87 cases of abnormal liver function index and 192 cases of abnormal blood routine index, accounting for $9.06 \%$ and $20.00 \%$ respectively. Most of them merged in co-infection groups. Compared with pure infections, the liver function and blood routine index of co-infected patients is higher. And the comparison results make statistical significance; $\mathrm{P}$ is less than 0.05 at least. At the same time, most of the comparisons between the co-infection groups made a statistical significance; $\mathrm{P}$ is less than 0.05 on average. Disease distribution and laboratory test results show as follows.

Table 1 when comparing with gender, we can know $\chi^{2}=559.01, \mathrm{P}=0.00012$. The differences of prevalence rate between male and female make a statistical significance. At the age distribution, the differences of prevalence rate between people above the age of 40 and people under the age of 40 also make a statistical significance $\chi^{2}=357.08, \mathrm{P}=0.000187$.

Table 2 shows that patients with low body resistance more easily infect other viruses and bacteria. The common diseases are tuberculosis merge of HIV infection, tuberculosis merger of fungal infection and multiple infections of HIV and fungi.

\section{Table 1. Gender and age distribution of national tuberculosis control project.}

\begin{tabular}{|c|c|c|c|c|c|c|c|c|c|c|c|c|c|c|c|c|}
\hline \multirow[b]{3}{*}{ Gender } & \multirow{2}{*}{\multicolumn{2}{|c|}{ Total cases }} & \multicolumn{14}{|c|}{ Age distribution (\%) } \\
\hline & & & \multicolumn{2}{|c|}{$\begin{array}{c}0-20 \\
\text { years old }\end{array}$} & \multicolumn{2}{|c|}{$\begin{array}{c}21-30 \\
\text { years old }\end{array}$} & \multicolumn{2}{|c|}{$\begin{array}{c}31-40 \\
\text { years old }\end{array}$} & \multicolumn{2}{|c|}{$\begin{array}{c}41-50 \\
\text { years old }\end{array}$} & \multicolumn{2}{|c|}{$\begin{array}{c}51-60 \\
\text { years old }\end{array}$} & \multicolumn{2}{|c|}{$\begin{array}{c}61-70 \\
\text { years old }\end{array}$} & \multicolumn{2}{|c|}{$\begin{array}{c}\text { Over } 71 \\
\text { years old }\end{array}$} \\
\hline & ્ֻల & 总 & 岕 & 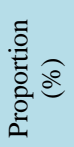 & $\begin{array}{l}\mathscr{U} \\
\tilde{U} \\
\tilde{U}\end{array}$ & 兽 & $\begin{array}{l}\mathscr{U} \\
\tilde{U}\end{array}$ & 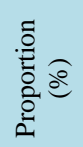 & ్ֶల & 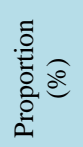 & $\begin{array}{l}\mathscr{U} \\
\tilde{U} \\
\tilde{U}\end{array}$ & 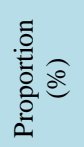 & ֻٓ & 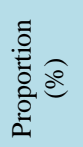 & $\underset{\mathscr{U}}{\mathscr{U}}$ & 을 \\
\hline Male & 739 & 76.98 & & & & & & & & & & & & & & \\
\hline Female & 221 & 23.02 & 28 & 2.92 & 132 & 13.75 & 141 & 14.69 & 100 & 17.50 & 151 & 19.89 & 189 & 19.69 & 139 & 4.48 \\
\hline
\end{tabular}


Table 3 and Table 4 show that blood routine index of co-infected patients in National Tuberculosis Control Project Guangxi is higher than pure TB infection. When we compare TB co-infection group with pure TB infection group, if $\mathrm{P}$ is less than 0.01 on average, the items show the statistical significance. If $\mathrm{P}$ is more than 0.05 , the items will not, such as RBC in TB complicated by HIV infection group, TB merge of FV group and pure TB infection group. When we compare TB complicated by HIV infection group with TB merge of HIV and FV group, WBC, NE, HBG and PLT make statistical significance, $\mathrm{P}<0.01$ on average. Comparison between TB merge of FV and TB merge of HIV and FV group, all items make statistical significance, $\mathrm{P}<0.01$ on average, except for LYM which is more than 0.05. From these results, we can draw a conclusion that the higher coinfection degree is, the more the number of pathogenic bacteria and the higher blood routine index is.

Table 5 and Table 6 show liver function of co-infected patients is higher than pure TB infection. When we compare all TB co-infection group with pure TB infection group, comparison of TBA in TB complicated by HIV infection group, TB merge of FV group and pure TB infection group, there is no statistical significance as $\mathrm{P}>$ 0.05. Comparison of DBIL in TB complicated by HIV infection group and pure TB infection group has no statistical significance as $\mathrm{P}>0.05$. The same as comparison of ALB in TB merge of HIV and FV group and pure TB infection group as $\mathrm{P}>0.05$. From these results, we can draw a conclusion that liver function of co-infected TB patients is higher than pure TB infection. In all of the co-infection groups, all the items of liver function make statistical significance as $\mathrm{P}<0.01$ on average which suggests that different complications of liver function indexes have different degrees of change and they rise with the infection degree.

\section{Discussions}

Tuberculosis is an infectious disease which is caused by mycobacterium tuberculosis infection. It is clinically in chronic process. It begins with low fever, malaise and night sweats, accompanying cough, expectoration, hemopstysis, etc. Mycobacterium tuberculosis can invade bodies’ organs, causing organs tuberculosis. And mycobacterium tuberculosis tends to invade lungs, leading to pulmonary tuberculosis. In the past, we regarded tuberculosis as phthisis or white plague, which was a kind of infectious disease which existed for a long term. China is one of the areas prone to tuberculosis. And it is also one of the 22 countries under heavy economic burden. According to the data, there are about a third of Chinese who have been infected with mycobacterium tuberculosis. The number is over four hundred million. At present, there are approximately five million tuberculosis patients and most of them are over 25 years old. The numbers of smear-positive patients exceed 1.5 million. Every

Table 2. Distribution of 960 cases of patients in national tuberculosis control project.

\begin{tabular}{cccccccc}
\hline \multicolumn{2}{c}{ Pure TB infection } & \multicolumn{2}{c}{$\begin{array}{c}\text { TB complicated by HIV } \\
\text { infection }\end{array}$} & \multicolumn{2}{c}{ TB merger of fungal infection } & \multicolumn{2}{c}{ TB merge of HIV and FV } \\
\hline Cases & $\begin{array}{c}\text { Proportion } \\
(\%)\end{array}$ & Cases & $\begin{array}{c}\text { Proportion } \\
(\%)\end{array}$ & Cases & $\begin{array}{c}\text { Proportion } \\
(\%)\end{array}$ & Cases & $\begin{array}{c}\text { Proportion } \\
(\%)\end{array}$ \\
\hline 731 & 76.14 & 21 & 2.19 & 196 & 20.42 & 12 & 1.25 \\
\hline
\end{tabular}

TB: tuberculosis; HIV: human immunodeficiency virus; FV: fungi.

Table 3. Comparison of blood routine index of co-infected patients in national tuberculosis control project.

\begin{tabular}{|c|c|c|c|c|c|c|c|c|}
\hline $\begin{array}{l}\text { Co-infection } \backslash \text { blood } \\
\text { routine index }\end{array}$ & $\begin{array}{c}\text { WBC } \\
\left(\times 10^{9} / \mathrm{L}\right)\end{array}$ & $\begin{array}{c}\mathrm{NE} \\
\left(\times 10^{9} / \mathrm{L}\right)\end{array}$ & $\begin{array}{c}\text { LYM } \\
\left(\times 10^{9} / \mathrm{L}\right)\end{array}$ & $\begin{array}{c}\mathrm{EO} \\
\left(\times 10^{9} / \mathrm{L}\right)\end{array}$ & $\begin{array}{c}\text { EA } \\
\left(\times 10^{9} / \mathrm{L}\right)\end{array}$ & $\begin{array}{c}\mathrm{RBC} \\
\left(\times 10^{12} / \mathrm{L}\right)\end{array}$ & $\begin{array}{l}\text { HBG } \\
(\mathrm{g} / \mathrm{L})\end{array}$ & $\begin{array}{c}\text { PLT } \\
\left(\times 10^{9} / \mathrm{L}\right)\end{array}$ \\
\hline $\begin{array}{l}\text { Pure TB } \\
\text { infection }\end{array}$ & $5.7 \pm 0.0014$ & $3.18 \pm 0.0012$ & $1.59 \pm 0.0007$ & $0.36 \pm 0.0037$ & $0.023 \pm 0.00024$ & $4.87 \pm 0.001$ & $133.39 \pm 0.023$ & $230.23 \pm 0.079$ \\
\hline $\begin{array}{c}\text { TB } \\
\text { complicated by } \\
\text { HIV infection }\end{array}$ & $7.64 \pm 0.04$ & $4.64 \pm 0.7$ & $1.88 \pm 0.54$ & $0.44 \pm 0.35$ & $0.028 \pm 0.029$ & $4.84 \pm 0.63$ & $136.92 \pm 14.65$ & $237.23 \pm 42.28$ \\
\hline $\begin{array}{l}\text { TB merge } \\
\text { of FV }\end{array}$ & $8.83 \pm 0.0049$ & $5.48 \pm 0.0068$ & $1.96 \pm 0.0031$ & $0.54 \pm 0.0022$ & $0.031 \pm 0.0001$ & $4.87 \pm 0.0036$ & $131.37 \pm 0.084$ & $298.98 \pm 0.45$ \\
\hline $\begin{array}{l}\text { TB merge of HIV } \\
\text { and FV }\end{array}$ & $13.92 \pm 0.02$ & $10.72 \pm 0.21$ & $1.96 \pm 0.076$ & $0.26 \pm 0.015$ & $0.028 \pm 0.0019$ & $4.51 \pm 0.061$ & $116.08 \pm 1.37$ & $366.3 \pm 7.26$ \\
\hline
\end{tabular}

WBC: white blood cell; NE: norepinephrine; LYM: lymphocyte; EO: basophile granulocyte; EA: eosinophile granulocyte; RBC: red blood cell; HBG: hemoglobin; PLT: platelet. 
Table 4. Comparison results of blood routine index of co-infected patients in national tuberculosis control project, showing with $\mathrm{T}$ or $\mathrm{P}$.

\begin{tabular}{ccccccc}
\hline Items & $\begin{array}{c}\text { Pure TB infection } \\
\text { and TB complicated } \\
\text { by HIV infection }\end{array}$ & $\begin{array}{c}\text { Pure TB } \\
\text { infection and TB } \\
\text { merge of FV }\end{array}$ & $\begin{array}{c}\text { Pure TB infection } \\
\text { and TB merge of } \\
\text { HIV and FV }\end{array}$ & $\begin{array}{c}\text { TB complicated by } \\
\text { HIV infection and } \\
\text { TB merge of FV }\end{array}$ & $\begin{array}{c}\text { TB complicated by } \\
\text { HIV infection and TB } \\
\text { merge of HIV and FV }\end{array}$ & $\begin{array}{c}\text { TB merge of FV } \\
\text { and TB merge of } \\
\text { HIV and FV }\end{array}$ \\
\hline WBC & 1312.86 & $15,137.14$ & $10,068.66$ & 102.78 & 538.84 & 277.798 \\
NE & $(0.0000196)$ & $(0.0000017)$ & $(0.00000256)$ & $(0.00025)$ & $(0.000048)$ & $(0.00001)$ \\
& $(0.000447)$ & $(0.000003)$ & $(0.0000255)$ & $1(0.00088)$ & 17.1275 & 359.7801 \\
LYM & 14.8582 & 2961.464 & 136.9105 & 2.082 & $0.0015)$ & $(0.0000717)$ \\
& $(0.0017)$ & $(0.0000087)$ & $(0.000188)$ & $(0.0124)$ & $(0.1933)$ & 0.000 \\
EO & 6.3112 & 650.7755 & 83.7632 & 4.0791 & 1.7685 & $(1.0000)$ \\
& $(0.00409)$ & $(0.0000396)$ & $(0.000308)$ & $(0.00632)$ & $(0.0554)$ & 231.122 \\
EA & 4.7643 & 456.0277 & 51.7212 & 1.4771 & 0.000 & $(0.0001116)$ \\
& $(0.0054)$ & $(0.000057)$ & $(0.000499)$ & $(0.0663)$ & $(1.0000)$ & 22.4327 \\
RBC & 1.3175 & $0.000(1.000)$ & 164.9687 & 0.6799 & 1.7974 & $(0.00115)$ \\
& $(0.0744)$ & $(0.000156)$ & $(0.1441)$ & $(0.0545)$ & 83.3465 \\
HBG & 6.6664 & 575.3804 & 353.0369 & 5.40877 & 4.8823 & $(0.000309)$ \\
& $(0.00387)$ & $(0.0000448)$ & $(0.0000731)$ & $(0.00477)$ & $(0.00528)$ & 154.271 \\
PLT & 4.5805 & 3916.97 & 526.494 & 20.8437 & 10.4185 & $(0.0001672)$ \\
& $(0.00563)$ & $(0.0000066)$ & $(0.000049)$ & $(0.00124)$ & $(0.00248)$ & 130.564 \\
\hline
\end{tabular}

TB: tuberculosis; HIV: human immunodeficiency virus; FV: fungi; WBC: white blood cell; NE: neutrophilicgranulocyte; LYM: lymphocyte; RBC: red blood cell; HBG: hemoglobin; PLT: platelet.

Table 5. Comparison of liver function indexes of co-infected patients in national tuberculosis control project.

\begin{tabular}{cccccccc}
\hline $\begin{array}{c}\text { Co-infection } \backslash \text { iver } \\
\text { function items }\end{array}$ & $\begin{array}{c}\text { TBIL } \\
(\mathrm{umol} / \mathrm{L})\end{array}$ & $\begin{array}{c}\mathrm{DBIL} \\
(\mathrm{umol} / \mathrm{L})\end{array}$ & $\begin{array}{c}\text { IDIL } \\
(\mathrm{umol} / \mathrm{L})\end{array}$ & $\begin{array}{c}\text { ALT } \\
(\mathrm{u} / \mathrm{L})\end{array}$ & $\begin{array}{c}\text { AST } \\
(\mathrm{u} / \mathrm{L})\end{array}$ & $\begin{array}{c}\text { ALB } \\
(\mathrm{g} / \mathrm{L})\end{array}$ & $\begin{array}{c}\text { TBA } \\
(\mathrm{umol} / \mathrm{L})\end{array}$ \\
\hline $\begin{array}{c}\text { Pure TB infection } \\
\text { TB complicated by } \\
\text { HIV infection }\end{array}$ & $7.82 \pm 5.24$ & $4.56 \pm 3.62$ & $3.27 \pm 1.99$ & $13.87 \pm 2.56$ & $21.58 \pm 7.38$ & $43.3 \pm 4.26$ & $5.22 \pm 11.63$ \\
TB merge of FV & $9.26 \pm 0.03$ & $3.84 \pm 0.02$ & $5.42 \pm 0.19$ & $33.95 \pm 0.21$ & $39.76 \pm 0.26$ & $44.94 \pm 0.03$ & $6.03 \pm 0.06$ \\
$\begin{array}{c}\text { TB merge of HIV } \\
\text { and FV }\end{array}$ & $16.51 \pm 0.72$ & $7.18 \pm 0.46$ & $8.85 \pm 0.35$ & $179.28 \pm 5.31$ & $161.68 \pm 7.78$ & $43.86 \pm 0.86$ & $17.84 \pm 1.96$ \\
\hline
\end{tabular}

TB: tuberculosis; HIV: human immunodeficiency virus; FV: fungi; TBIL: total bilirubin; DBIL: direct bilirubin; IDIL: indirect bilirubin; ALT: aminoleucine transferase; AST: glutamic-oxalacetic transaminase; ALB: albumin; TBA: total bile acid.

year, about 130,000 people die of tuberculosis, and the average age is around 55 years old. The research shows that about $10 \%$ of the mycobacterium tuberculosis infectious people are likely to be tuberculosis patients. If we don't take a good control of it, there will be about 50 million infected persons turning to tuberculosis patients [5]-[7] in the coming 10 years. Therefore, it's an extremely serious job for China to prevent and control tuberculosis. And its screening procedure can never be ignored.

Tuberculosis tends to do harm to all body organs, but it's mainly priority lungs. People getting infected with mycobacterium tuberculosis are not necessarily developed into tuberculosis. That will only happen in the case of low body resistance. What's a worse, patient may infect other viruses and bacteria. The common diseases are tuberculosis merge of HIV infection, tuberculosis merger of fungal infection and multiple infections of HIV and fungi. Under this circumstance, it will lead to drug resistance and depressing treatment. Tuberculosis pathology represents as tuberculosis nodules or caseous necrosis. And a lot of studies show that it tends to form cavities [7]-[10]. Tuberculosis disturbs human activities and even their lives. Many researches show that there is possibility of TB co-infected with other diseases, but not there are no report on TB combines with routine blood, main index of liver function. Therefore, this study for joint system analysis has important practical significance.

The study shows that males' prevalence rate is higher than females' among these collected patients in Guangxi, a district of national TB controlling project. The differences of prevalence rate between male and female make a statistical significance. If $P$ is less than 0.001 , it means males' TB prevalence rate is higher than females' 
Table 6. Comparison results of liver function indexes of co-infected patients in national tuberculosis control project, showing with $\mathrm{T}$ or $\mathrm{P}$.

\begin{tabular}{|c|c|c|c|c|c|c|}
\hline Items & $\begin{array}{c}\text { Pure TB } \\
\text { infection and TB } \\
\text { complicated by } \\
\text { HIV infection }\end{array}$ & $\begin{array}{c}\text { Pure TB } \\
\text { infection and TB } \\
\text { merge of FV }\end{array}$ & $\begin{array}{c}\text { Pure TB } \\
\text { infection and TB } \\
\text { merge of } \\
\text { HIV and FV }\end{array}$ & $\begin{array}{c}\text { TB complicated } \\
\text { by HIV infection } \\
\text { and TB } \\
\text { merge of FV }\end{array}$ & $\begin{array}{l}\text { TB complicated by } \\
\text { HIV infection and TB } \\
\text { merge of HIV } \\
\text { and FV }\end{array}$ & $\begin{array}{c}\text { TB merge of FV } \\
\text { and TB merge of } \\
\text { HIV and FV }\end{array}$ \\
\hline TBIL & $\begin{array}{c}2.962267 \\
(0.008709)\end{array}$ & $\begin{array}{c}3.84579 \\
(0.006709)\end{array}$ & $\begin{array}{c}5.74023 \\
(0.04495)\end{array}$ & $\begin{array}{c}47.3944 \\
(0.000544)\end{array}$ & $\begin{array}{c}23.12903 \\
(0.001115)\end{array}$ & $\begin{array}{c}144.327 \\
(0.00017)\end{array}$ \\
\hline DBIL & $\begin{array}{l}0.809499 \\
(0.12106)\end{array}$ & $\begin{array}{c}2.78342 \\
(0.009269)\end{array}$ & $\begin{array}{c}2.5052 \\
(0.0102986)\end{array}$ & $\begin{array}{l}44.96408 \\
(0.00056)\end{array}$ & $\begin{array}{l}12.4105 \\
(0.0020)\end{array}$ & $\begin{array}{c}103.933 \\
(0.00024)\end{array}$ \\
\hline IDIL & $\begin{array}{c}5.56841 \\
(0.00449)\end{array}$ & $\begin{array}{c}15.1013 \\
(0.001655)\end{array}$ & $\begin{array}{c}9.70471 \\
(0.002576)\end{array}$ & $\begin{array}{l}6.158098 \\
(0.00406)\end{array}$ & $\begin{array}{c}33.1776 \\
(0.00075)\end{array}$ & $\begin{array}{c}57.1625 \\
(0.00044)\end{array}$ \\
\hline ALT & $\begin{array}{c}94.3211 \\
(0.000265)\end{array}$ & $\begin{array}{c}109.671 \\
(0.000228)\end{array}$ & $\begin{array}{c}216.762 \\
(0.0001153)\end{array}$ & $\begin{array}{l}541.1675 \\
(0.00005)\end{array}$ & $\begin{array}{c}97.4355 \\
(0.00026)\end{array}$ & $\begin{array}{c}392.868 \\
(0.000064)\end{array}$ \\
\hline AST & $\begin{array}{c}29.3435 \\
(0.00085)\end{array}$ & $\begin{array}{c}34.4685 \\
(0.00073)\end{array}$ & $\begin{array}{c}65.1746 \\
(0.00038)\end{array}$ & $\begin{array}{c}224.0877 \\
(0.000112)\end{array}$ & $\begin{array}{c}53.1414 \\
(0.00047)\end{array}$ & $\begin{array}{c}225.82 \\
(0.00011)\end{array}$ \\
\hline ALB & $\begin{array}{l}1.22546 \\
(0.0204)\end{array}$ & $\begin{array}{c}5.3875 \\
(0.004640)\end{array}$ & $\begin{array}{l}0.45493 \\
(0.2154)\end{array}$ & $\begin{array}{c}24.1817 \\
(0.001034)\end{array}$ & $\begin{array}{c}2.864743 \\
(0.0087)\end{array}$ & $\begin{array}{l}18.08069 \\
(0.00138)\end{array}$ \\
\hline TBA & $\begin{array}{c}1.7600 \\
(0.05568)\end{array}$ & $\begin{array}{l}0.97468 \\
(0.1005)\end{array}$ & $\begin{array}{c}3.75569 \\
(0.006656)\end{array}$ & $\begin{array}{c}51.3691 \\
(0.00049)\end{array}$ & $\begin{array}{c}15.8923 \\
(0.01573)\end{array}$ & $\begin{array}{c}86.9642 \\
(0.00029)\end{array}$ \\
\hline
\end{tabular}

TB: tuberculosis; HIV: human immunodeficiency virus; FV: fungi; TBIL: total bilirubin; DBIL: direct bilirubin; IDIL: indirect bilirubin; ALT: aminoleucine transferase; AST: glutamic-oxalacetic transaminase; ALB: albumin; TBA: total bile acid.

or females' screening rate is less than males'. While at the age of distribution of disease, TB mainly focuses on the people over 40 years old, which is consistent with some related reports [2]-[4]. The differences of prevalence rate between people above the age of 40 and people under the age of 40 make a statistical significance, $\mathrm{P}$ is less than 0.001. And it also explains the onset age of TB in this region mainly focused on the elder ages, which might be related to their low resistance and lacking consciousness of health prevention. In the distribution of complication, this research can be divided into the following parts that are 731 cases of pure TB infections, 21 cases of TB merge of HIV, 196 cases merge of fungal infection and 12 cases of HIV merge of fungi infection. These suggests that TB patients with various co-infections. In the laboratory tests, there are 87 cases of abnormal liver function index and 192 cases of abnormal blood routine index. Most of them merged in co-infection groups. Compared with pure infections, the liver function and blood routine index of co-infected patients is higher. And the comparison results also make statistical significance; $\mathrm{P}$ is less than 0.05 at least. At the same time, most of the comparisons between the co-infection groups make a statistical significance; $\mathrm{P}$ is less than 0.05 on average. This research shows that the liver function and blood routine index of co-infected TB patients is higher than pure TB infection. And they change to different extent, rising with the infection degree.

\section{Conclusion}

In conclusion, the national TB controlling project for the regional patients mainly concentrated on elder ages. The co-infected patients account for a large proportion, their liver function and blood routine index are higher than pure TB infection. What mentioned above indicates us to analyze mycobacterium tuberculosis comprehensively and check in clinical treatment reasonably. Only in this way, can we work out a good treatment plan for satisfactory therapeutic results.

\section{Limitations}

This research is mainly for the tuberculosis control project in Guangxi region. The results can only reflect the situation of this region, not always can represent the national TB situation. It must invest a lot to invest more regions to know the whole national TB situation.

\section{Acknowledgements}

During this topic research process, we got help from many departments and individuals, such as the projects of science and technology, and our hospital of Infectious Diseases and Infection Clinic, and other personnel not 
involved in this project research, all of them offered a great support and help in this research. Now here, all of members of this research group show our deepest appreciation to them, and wish them good health and everything goes well.

\section{Contributions}

Guosheng Su is responsible for the total project organization coordinated implementation. Xiaolu Luo, Wanhong Huang, Shanqiu Wei, Ning Xie and Meirong Xu participated in research. Xiaolu Luo, Wanhong Huang and Shanqiu Wei were responsible for case collection and data statistics. Ning Xie and Meirong Xu were responsible for clinical detection and data processing.

\section{Fund Projects}

Major projects of this study are science and technology (No. 201109047C) in 2011of Nanning city Guangxi province; Province Science and Technology Project in Nanning Guangxi (No. 20123164) in 2012; Guangxi health department self-financing projects in 2012 (No. Z20120621).

\section{References}

[1] Zhao, Y.-L., Lin, X.-Q., Huang, X.-P., et al. (2012) Nanning City TB Control Epidemiological Effect Evaluation during 2003 to 2009. MPM, 33, 547-549.

[2] Li, J.-Q., Yan, J. and Liu, H. (2013) Minhang Jiangchuan Community in Shanghai, TB Prevention Cases from 2009 to 2012. JOAH, 29, 2043-2045.

[3] Shao, J.-Y. and Li, P. (2013) Lianhu District in Xian, TB Control Affection during 2004 to 2011. JOAH, 29, 465-469.

[4] Lu, Z.-L., Yin, L.-Y., Yao, H., et al. (2013) 2002-2012, Yizhou City, Guangxi Zhuang Autonomous Region, Analysis of TB Control Affection during 2002 to 2012. JOAH, 29, 1766-1768.

[5] Li, Y., Zhang, F., Gao, F.-H., et al. (2014) Zibo City in Shandong Province from 2005 to 2011 the Analysis of Tuberculosis Epidemic. MPM, 41, 1130-1134.

[6] Chen, Y.-G., Lu, J., Ma, L., et al. (2012) Observation to Tuberculosis in Patients with HIV Infection in Urunchi China. MPM, 39, 5410-5412.

[7] Yang, M., Yue, J., Li, X., et al. (2012) Analysis of TB Combined HIV/AIDS Infection. JCL, 17, 845-846.

[8] Han, X.-Q., Yin, J.-D., Wu, S.-M., et al. (2013) Comparison of Organism Redox State between AIDS Tuberculosis and Pure TB Infected Patients. JCL, 18, 427-428.

[9] Zhang, H.-Q., Zhang, C.-X., Wen, Z.-F., et al. (2012) Analysis of Factors Associated with Occurrence of Nosocomial Infection in Hospitalized Patients with Tuberculosis (TB). MPM, 39, 6417-6419.

[10] He, B.-S., Li, S.-C., Zhang, X.-X., et al. (2012) Analysis of 1297 Sputum Smear-Positive Tuberculosis Drug Resistance. JHM, 23, 121-123. 